\title{
Better to exist: A reply to Benatar
}

\author{
Seth D. Baum
}

Department of Geography and Rock Ethics Institute, Pennsylvania State University. http://sethbaum.com

Journal of Medical Ethics, vol. 34, no. 12, pages 875-876, 2008.

\section{A recent exchange on Benatar's book Better never to have been between Doyal and Benatar discusses Benatar's bold claim that people should not be brought into existence. Here, I expand the discussion of original position which the exchange focused on. I also discuss the asymmetries, between benefit and harm and between existent and non-existent, upon which Benatar's bold claim rests. In both discussions, I show how Benatar's bold claim can be rejected.}

In a recent book, ${ }^{1}$ Benatar has advanced a rather bold claim: that it is wrong to bring new people into existence. This claim was recently the subject of an exchange between Doyal ${ }^{2}$ and Benatar ${ }^{3}$ in this journal. In this article, I comment on this exchange and discuss parts of Benatar's argument that were not covered in the exchange. The first section, 'Original Position', discusses the Doyal-Benatar exchange. The second section, 'Asymmetries', discusses core arguments in Benatar's book not covered in the Doyal-Benatar exchange. Benatar's views, which I call 'antibirth utilitarianism', stem from his treatment of asymmetries between benefit and harm and between existent and non-existent. From the analysis in these two sections, I conclude that Benatar's bold claim can and, in my view, should be rejected.

Before beginning, it is helpful to note that this discussion exists entirely within variations of consequentialist welfarism. Readers who reject consequentialist welfarism might thus dismiss all of the arguments presented here. Within consequentialist welfarism, the variation concerns how much to value different types of welfare. Following Doyal, I use the terms benefit/harm to refer to positive/negative welfare. Differences between benefit/harm and other terms such as pleasure/pain or happiness/suffering are ignored here. 'Harm' here refers to a state of mind so unpleasant that a person experiencing it would prefer to not be conscious. This state is, for example, where anesthetic might be recommended. A life of nothing but harm thus might be considered 'a life worth not living' because the sum of experiences in this life is considered worse than the neutral 'experience' of never existing.

\section{Original Position}

The Doyal-Benatar exchange focuses on the original position thought experiment. In original position, members of society must choose an ethical framework as if they did not know which member of society they were. This ignorance prevents people from choosing frameworks which treat themselves better than others. Benatar claims that people in original position would prefer not coming into existence; Doyal rejects this claim.

Discussion of original position concerns which ethical framework individuals in the original position would choose. Two ethical frameworks are commonly cited here. The first 
framework is maximin, which claims that we should maximize the minimum level of welfare of a member of society. The second framework is expected utility maximization, ${ }^{i}$ which claims that we should maximize the expected value (average) of the levels of welfare of members of society.

Support for maximin frequently comes from a desire to help those worst off in society. Maximin's famous defense is Rawls's $A$ theory of justice. ${ }^{4}$ However, as Harsanyi ${ }^{5}$ persuasively shows, maximin has many unappealing consequences. For example, maximin recommends an extreme risk aversion, to the point that we would not make, say, routine travel given even an infinitesimal chance of fatal accident. Harsanyi instead defends expected utility maximization, a defense I find persuasive.

Benatar supports maximin. His use of maximin is yet another unappealing consequence of this ethical framework. ${ }^{\text {ii }}$ Benatar highlights that in decisions about how many people to bring into existence, maximin would recommend bringing zero people into existence. This is because if people are brought into existence, some of them would experience net harm: lives worth not living. One could thus raise the minimum welfare level to zero by bringing no people into existence. I agree with Benatar that maximin yields this result. However, unlike Benatar, I find this result to be yet another reason to reject maximin.

Benatar claims that 'Doyal does not discuss maximin in his review.' This is not so. Doyal supports an intermediate position between maximin and expected utility maximization: some harm is acceptable as long as enough there is much more benefit. Though I favor expected utility maximization to this intermediate position, the intermediate position is sufficient to reject Benatar's claim that people in original position would prefer not coming into existence.

Strict application of maximin in a world where harm exists (such as ours) entails not only not bringing new people into existence, as Benatar recommends, but also 'euthanizing' all existing people. This is because we all have at least some chance of experiencing harm at some point in our lives. To maximize our minimum subsequent experience, we should see to it that we stop having experiences. But Benatar does not make this recommendation. This is because of his treatment of asymmetries.

\section{Asymmetries}

Two asymmetries serve as the foundation of Benatar's bold claim that people should not be brought into existence: between benefit and harm and between existent and non-existent. The benefits/harms asymmetry claims that benefits and harms should be handled by ethical frameworks in fundamentally different ways. The existent/non-existent asymmetry claims that people who already exist and people who don't already exist should be handled by ethical frameworks in fundamentally different ways. Both asymmetries, as used by Benatar, reflect some reasonable intuitions but, upon closer inspection, are highly objectionable.

The benefits/harms asymmetry is commonly manifested (including in Benatar's writing) in the claim that no amount of benefit, however large, can make up for any amount of harm, however small. This claim comes from an intuition that while we have a duty to reduce harm,

\footnotetext{
${ }^{i}$ Expected utility maximization reduces to classical utilitarianism for circumstances in which no uncertainty exists.

"A similar discussion of maximin is found on p.173 of Leslie's The End of the World. ${ }^{6}$
} 
we have no duty to increase benefit. The corresponding ethical framework is often called 'negative utilitarianism'. ${ }^{7}$ Negative utilitarianism resembles maximin in its resolute focus on the worst off- as long as some of those worst off are in a state of harm, instead of just in a state of low benefit. Like maximin, negative utilitarianism can recommend that no one be brought into existence- and that all existing people be 'euthanized'. I find negative utilitarianism decidedly unreasonable: our willingness to accept some harm in order to enjoy the benefits of another day seems praiseworthy, not mistaken. I thus urge the rejection of this manifestation of the benefits/harms asymmetry.

The existent/non-existent asymmetry is commonly manifested (including in Benatar's writing)in the claim that, in decisions which might bring people into existence, the welfare of those would-be people don't count. This claim comes from an intuition that we cannot benefit or harm people by bringing them into existence, because if they don't come into existence, then there is no 'them' to benefit or harm. The corresponding ethical framework is often called 'person-affecting utilitarianism' ${ }^{8}$ This metaphysical trickery is unsatisfying. It seems quite reasonable that, all else equal, the entry into the world of some new, happy people can make the world a better place (or vice versa for unhappy people). Furthermore, person-affecting utilitarianism has troubling consequences such as permitting existing people to go on a frivolous binge even to the point of destroying the world for all would-be people. I thus urge the rejection of this manifestation of the existent/non-existent asymmetry.

Benatar supports both the benefits/harms asymmetry and the existent/non-existent asymmetry, but he does not do so uniformly. ${ }^{\text {iii }}$ He accepts the benefits/harms asymmetry for people who don't already exist but he rejects it for people who already exist. Alternatively (and equivalently), he accepts the existent/non-existent asymmetry for benefits but he rejects it for harms. In other words, he does not value benefits to people we could bring into existence, but he values harms to them as well as benefits and harms to existing people. This set of views is how he reaches his bold claim that new people should not be brought into existence but does not reach the claim that people who already exist should be 'euthanized'. This 'anti-birth utilitarianism' has received support from others as well, including Narveson ${ }^{9}$ and Vetter. ${ }^{10}$

If we reject both asymmetries, as I urge, then Benatar's bold claim disappears and we return to the more pedestrian discussions of which and how many people to bring into existence, and of course how to treat everyone once they come into existence. These discussions are important, but they need not be considered here. My one intention with this paper is to show that Benatar's bold claim can readily be rejected not just out of reflexive distaste for the claim but also out of sound ethical reasoning.

\section{Conclusion}

This discussion of the Doyal-Benatar exchange and Benatar's bold claim raises an important point about the methods of ethics. This point is that we must exercise much caution in any effort to 'universalize' our ethical intuitions, i.e. apply them to all circumstances, including circumstances quite different from where the intuitions came. Benatar arrives at a highly counter-intuitive claim, but he did begin with seemingly reasonable intuitions. However,

\footnotetext{
iii See e.g. p.30 of Better never to have been.
} 
counter-intuitive claims can be reached for every possible ethical framework. Some might call for ethical relativism so that our intuitions are never offended. I make no such call. I only seek to emphasize the profound consequences of our choice of framework and to encourage that this choice be made with great care.

\section{ACKNOWLEDGEMENTS}

Thanks to Jason Matheny for drawing my attention to the Doyal-Benatar debate, to Nick Hay for helping catch a mistake in a previous draft, and to two anonymous reviewers for helpful comments on an earlier draft of this article.

Competing interests: None

\section{REFERENCES}

1. Benatar D. Better never to have been: the harm of coming into existence. Oxford: Clarendon Press, 2006.

2. Doyal L. Is human existence worth its consequent harm? J Med Ethics 2007;33:573-6.

3. Benatar D. Grim news from the original position: a reply to Professor Doyal. J Med Ethics 2007;33:577.

4. Rawls J. A theory of justice. Cambridge, MA: Harvard University Press, 1971.

5. Harsanyi J. Can the Maximin Principle Serve as a Basis for Morality? A Critique of John Rawls's Theory. Amer Poli Sci Rev 1975; 69: 594-606.

6. Leslie J. The End of the World: The Science and Ethics of Human Extinction. London: Routledge, 1996.

7. Smart, R. Negative Utilitarianism. Mind 1958;67:542-543.

8. Arrhenius G. The Moral Status of Potential People. Mimeo, Stockholm University, 2006.

9. Narveson, J. Utilitarianism and New Generations. Mind 1967;76:62-72.

10. Vetter, H. Utilitarianism and New Generations. Mind 1971;80:301-302. 